\title{
Anion Photoelectron Spectroscopy of Aluminum Phosphide Clusters
}

\author{
Harry Gómez, Travis R. Taylor, ${ }^{\dagger}$ and Daniel M. Neumark* \\ Department of Chemistry, University of California, Berkeley, California 94720, and \\ Chemical Sciences Division, Lawrence Berkeley National Laboratory, Berkeley, California 94720
}

Received: February 12, 2001; In Final Form: May 7, 2001

\begin{abstract}
Anion photoelectron spectra of size selected $\mathrm{Al}_{x} \mathrm{P}_{y}{ }^{-}(x, y \leq 4)$ clusters have been taken at photodetachment wavelengths of $266 \mathrm{~nm}(4.661 \mathrm{eV}), 355 \mathrm{~nm}$ (3.493), and $416 \mathrm{~nm}(2.980 \mathrm{eV})$. The spectra show transitions to multiple neutral electronic states, and several of these bands are vibrationally resolved. We report electron affinities, term values, and vibrational frequencies of the corresponding neutral and anion states, where possible. Detailed assignments are proposed for the $\mathrm{AlP}_{2}{ }^{-}, \mathrm{Al}_{2} \mathrm{P}^{-}$, and $\mathrm{Al}_{2} \mathrm{P}_{2}{ }^{-}$spectra with the aid of electronic structure calculations. Results are compared with comparably sized $\mathrm{Ga}_{x} \mathrm{P}_{y}{ }^{-}$and $\mathrm{In}_{x} \mathrm{P}_{y}{ }^{-}$clusters.
\end{abstract}

\section{Introduction}

Semiconductor clusters have been the subject of intense experimental and theoretical investigations during the last 20 years. Research in this area is motivated by the desire to understand how properties of macroscopic semiconductors that make them so important in the electronics industry are affected when they are greatly reduced in size. Studies of semiconductor clusters have been performed in both the nanoscale and molecular size regimes in order to understand how the structural and spectroscopic properties of these species evolve with size. The nanoscale experiments ${ }^{1,2}$ have primarily explored how finite size alters the properties of bulk materials, while experiments in the molecular size regime aim at a detailed understanding of the much more abrupt changes in structure and spectroscopy as a cluster is built up from its elemental constituents one atom at a time. The latter studies have been greatly aided by the development of new theoretical methods and faster computers, enabling more complex and accurate calculations on ground and excited states and allowing more detailed comparison with experiments.

One of the most powerful experimental tools in the study of clusters has been anion photoelectron spectroscopy (PES), a technique that yields the electronic and vibrational spectroscopy of size-selected clusters. ${ }^{3}$ This method and its higher-resolution counterpart, zero electron kinetic energy (ZEKE) photodetachment spectroscopy, have been applied to both elemental ${ }^{4-11}$ and binary $^{12-15}$ semiconductor clusters. Recent work in our group has focused on III-V semiconductor clusters; results have been reported for $\mathrm{B}_{x} \mathrm{~N}_{y},{ }^{16-18} \mathrm{Ga}_{x} \mathrm{P}_{y},{ }^{19}$ and $\operatorname{In}_{x} \mathrm{P}_{y}$ clusters ${ }^{20}$ with as many as 27 atoms. In this publication, we report anion photoelectron spectra of aluminum phosphide clusters $\mathrm{Al}_{x} \mathrm{P}_{y}^{-}$, with $x, y \leq 4$.

AlP clusters are attractive targets of study compared to III $-\mathrm{V}$ clusters with heavier atoms because they have higher vibrational frequencies, facilitating the observation of vibrational progressions in their photoelectron spectra. In addition, the smaller number of electrons makes them more amenable to electronic structure calculations. While no experimental studies have been performed to date on AlP clusters, a series of electronic structure calculations have predicted that small AlP clusters adopt the

\footnotetext{
* Corresponding author.

† Current address: Lam Research, 47131 Bayside Parkway, Fremont, CA 94538.
}

two- and three-dimensional structures characteristic of $\mathrm{Si}_{n}{ }^{9}$ and $\mathrm{Ga}_{x} \mathrm{As}_{y}{ }^{21,22}$ clusters rather than the linear geometries found for small carbon ${ }^{23}$ and $\mathrm{B}_{x} \mathrm{~N}_{y}$ clusters. ${ }^{16,17}$

$\mathrm{Ab}$ initio calculations on properties of $\mathrm{Al}_{x} \mathrm{P}_{y}$ clusters have been carried out by several groups. ${ }^{24-32}$ Raghavachari ${ }^{26}$ calculated minimum-energy structures for $(\mathrm{AlP})_{n}$ using Hartree-Fock (HF) and fourth-order Møller-Plesset (MP4) perturbation theory, followed by quadratic configuration interaction QCISD(T). Tomasulo and Ramakrishna ${ }^{28}$ used density functional theory (DFT) to explore structures for $(\mathrm{AlP})_{n}$ clusters up to 12 atoms, finding significantly different structures than those for $\mathrm{Si}_{2 n}$ clusters for $n \geq 3$. Feng and Balasubramanian ${ }^{29,30,32}$ performed higher-level ab initio calculations on a series of $\mathrm{Al}_{x} \mathrm{P}_{y}$ neutral and charged clusters with four or fewer atoms. They calculated ground and excited-state geometries and energies using complete active space self-consistent field (CASSCF) and multireference singles-doubles configuration interaction (MRSDCI) levels of theory with a basis set composed of relativistic effective core potentials and valence Gaussian basis sets. Archibong et al. ${ }^{31}$ calculated structures and detachment energies for $\mathrm{AlP}_{2}{ }^{-}, \mathrm{Al}_{2} \mathrm{P}_{2}{ }^{-}$, and their neutral counterparts at the DFT and coupled cluster singles and doubles (CCSD(T)) levels of theory. They reported ground and excited-state electronic energies and vibrational frequencies for the neutral and anionic species. Archibong's work differs from those of Balasubramanian in that $\mathrm{Al}_{2} \mathrm{P}_{2}$ was not restricted to $D_{2 h}$ (planar rhombic) symmetry, and indeed, $\mathrm{Al}_{2} \mathrm{P}_{2}{ }^{-}$was found to have a nonplanar ground state.

The spectra reported in this paper represent the first experimental study of aluminum phosphide clusters. We obtain electron affinities (EAs), vertical detachment energies for the ground and low-lying electronic states of the neutral clusters, and vibrational frequencies in some cases. In general, photoelectron spectra of $\mathrm{Al}_{x} \mathrm{P}_{y}{ }^{-}$are reasonably similar to isoelectronic species $\mathrm{Ga}_{x} \mathrm{As}_{y}{ }^{-}$and $\mathrm{In}_{x} \mathrm{P}_{y}{ }^{-}$. Photoelectron spectra of the small clusters are compared directly to ab initio calculations by Feng and Balasubramanian ${ }^{29,30,32}$ and Archibong et al. ${ }^{31}$ in order to assign the observed electronic transitions.

\section{Experimental Section}

The anion photoelectron spectrometer used in this study has been described in detail previously. ${ }^{33,34}$ Cluster anions are generated in a laser ablation/pulsed molecular beam source. A 
rotating and translating pellet made of 50-80\% aluminum powder-200 mesh (Aldrich), 10-30\% red phosphorus (Aldrich), and $5-20 \% \mathrm{KBr}$ (Fisher Scientific) is ablated with the second harmonic $(532 \mathrm{~nm})$ of a pulsed Nd:YAG laser. The laser pulses are typically $5.0-7.5 \mathrm{~mJ} /$ pulse and are focused onto the target with a $50 \mathrm{~mm}$ lens. The resulting plasma is entrained in a supersonic beam of argon. The gas pulse continues to travel through a 1.75-in. long copper clustering channel cooled with liquid nitrogen and then passes through a skimmer into a differentially pumped region. The cooling channel ${ }^{35}$ reduces spectral congestion in the PE spectra from vibrationally excited anions.

Negative ions in the beam are extracted perpendicular to their flow direction by a pulsed electric field and injected into a linear reflectron time-of-flight (TOF) mass spectrometer; the ion beam energy is $2.5 \mathrm{keV}$, and the mass spectrometer resolution $m / \Delta m$ $\approx 2000$. Mass-selected anions are selectively photodetached by a pulsed laser operating at wavelengths of $266(4.661 \mathrm{eV}), 355$ (3.493 eV), and $416 \mathrm{~nm}(2.980 \mathrm{eV})$. The photon wavelengths 266 and $355 \mathrm{~nm}$ were obtained by frequency quadrupling and tripling the fundamental of a pulsed Nd:YAG laser. To generate light at $416 \mathrm{~nm}$, we passed the third harmonic through a Raman cell filled with hydrogen at high pressure (325 psig). The electron kinetic energy (eKE) distribution is determined by TOF analysis in a $1 \mathrm{~m}$ field-free flight tube. The energy resolution is $8-10 \mathrm{meV}$ at $0.65 \mathrm{eV}$ eKE and degrades as $(\mathrm{eKE})^{3 / 2}$ at higher eKE.

The angular dependence of the photodetachment intensity for polarized light and randomly oriented molecules is given by ${ }^{36}$

$$
\frac{\mathrm{d} \sigma}{\mathrm{d} \Omega}=\frac{\sigma_{\text {total }}}{4 \pi}\left[1+\frac{\beta(\mathrm{eKE})}{2}\left(3 \cos ^{2} \theta-1\right)\right]
$$

where $\theta$ is the angle between the electric vector of the photon and the direction of electron ejection, $\sigma_{\text {total }}$ is the total photodetachment cross section, and $\beta(\mathrm{eKE})$ is the anisotropy parameter $(-1 \leq \beta \leq 2)$, which can be calculated using

$$
\beta=\frac{I_{0^{\circ}}-I_{90^{\circ}}}{\frac{1}{2} I_{0^{\circ}}+I_{90^{\circ}}}
$$

Here $I_{0^{\circ}}$ and $I_{90^{\circ}}$ are the intensities of the peak taken at the polarization angles $\theta=0^{\circ}$ and $90^{\circ}$. The laser polarization can be rotated with respect to the direction of electron detection with a half-wave plate. Each electronic photodetachment transition has a characteristic asymmetry parameter and this can be used to distinguish overlapping electronic transitions.

\section{Results}

Figure 1 shows photoelectron (PE) spectra of $12 \mathrm{Al}_{x} \mathrm{P}_{y}{ }^{-}$ clusters taken at a photon energy of $4.661 \mathrm{eV}$. In these spectra, the electron binding energy (eBE) is related to the internal energy of the anion and neutral by

$$
\mathrm{eBE}=\mathrm{EA}+E^{0}-E^{-}
$$

Here EA is the adiabatic electron affinity, and $E^{0}$ and $E^{-}$are the internal energies of the neutral and anion, respectively. The PE spectra show peaks corresponding to transitions to different electronic states in the neutral, with the lowest-lying state occurring at the lowest eBE. At $266 \mathrm{~nm}$, the $\mathrm{AlP}^{-}$and $\mathrm{Al}_{2} \mathrm{P}^{-}$ spectra show resolved vibrational structure, and less wellresolved vibrational features are also seen superimposed on the lowest eBE peaks in the $\mathrm{PE}$ spectra of $\mathrm{Al}_{3} \mathrm{P}^{-}, \mathrm{Al}_{2} \mathrm{P}_{3}{ }^{-}$, and $\mathrm{Al}_{3} \mathrm{P}_{3}{ }^{-}$. All the spectra in Figure 1 were taken at a laser

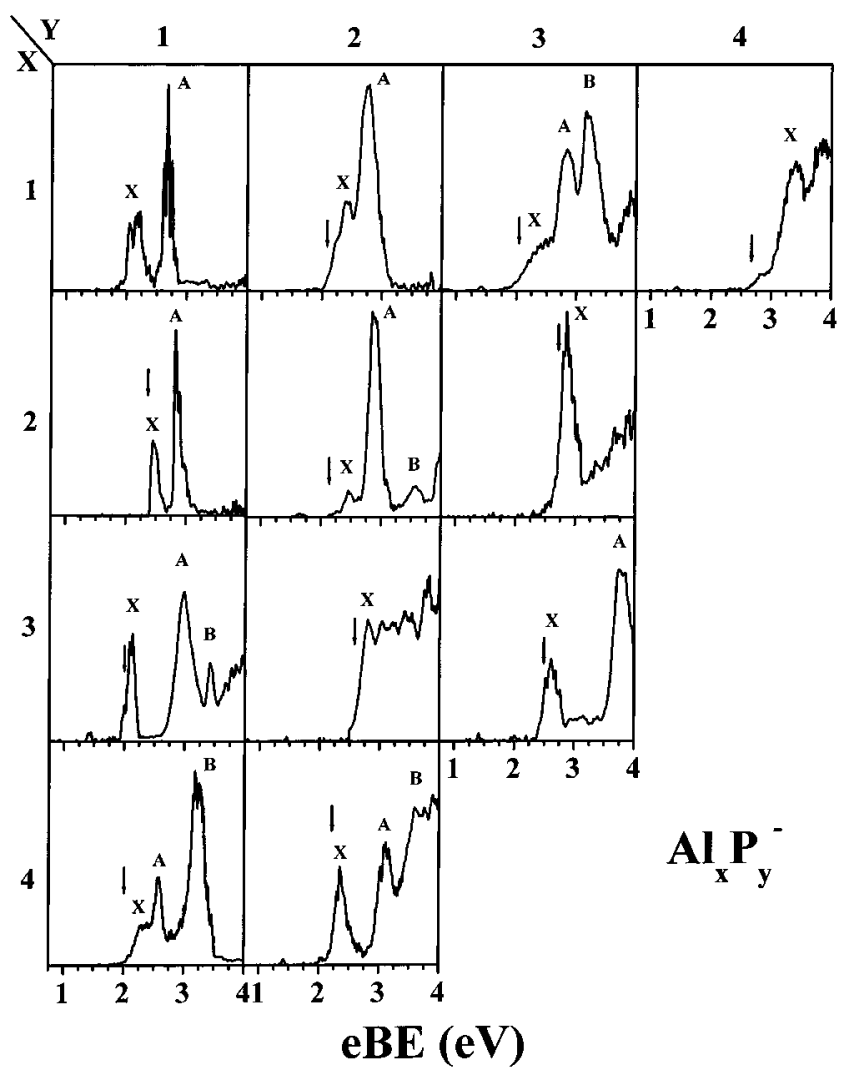

Figure 1. Photoelectron spectra of $\mathrm{Al}_{x} \mathrm{P}_{y}{ }^{-}$clusters taken at $266 \mathrm{~nm}$ $(4.661 \mathrm{eV})$. All spectra were taken at laser polarization of $\theta \approx 55^{\circ}$ with respect to the direction of electron collection

TABLE 1: Adiabatic Electron Affinities and Vertical Detachment Energies for $\mathrm{Al}_{x} \mathbf{P}_{y}{ }^{-}$

\begin{tabular}{ccccccc}
\hline & & & \multicolumn{5}{c}{$\begin{array}{c}\text { vertical detachment } \\
\text { energies }(\mathrm{eV})\end{array}$} \\
\cline { 4 - 7 } $\begin{array}{c}\text { cluster } \mathrm{Al}_{x} \mathrm{P}_{y} \\
(x, y)\end{array}$ & $\begin{array}{c}\text { mass } \\
(\mathrm{amu})\end{array}$ & $\begin{array}{c}\text { adiabatic EA } \\
(\mathrm{eV})\end{array}$ & $\mathrm{X}$ & $\mathrm{A}$ & $\mathrm{B}$ & $\mathrm{C}$ \\
\hline 1,1 & 58 & & & & & \\
1,2 & 89 & $1.933 \pm 0.007$ & 2.21 & 2.65 & & \\
1,3 & 120 & 2.06 & 2.58 & 2.85 & 3.21 & \\
1,4 & 151 & 2.64 & 2.93 & 3.40 & & \\
2,1 & 85 & $2.513 \pm 0.020$ & 2.55 & 2.83 & 2.98 & \\
2,2 & 116 & $2.15 \pm 0.10$ & 2.33 & 2.73 & 3.42 & 3.86 \\
2,3 & 147 & $2.739 \pm 0.020$ & 2.92 & & & \\
3,1 & 112 & $2.051 \pm 0.020$ & 2.12 & 2.99 & 3.43 & \\
3,2 & 143 & 2.58 & 2.82 & & & \\
3,3 & 174 & $2.450 \pm 0.020$ & 2.63 & 3.81 & & \\
4,1 & 139 & 1.98 & 2.40 & 2.58 & 3.21 & \\
4,2 & 170 & 2.25 & 2.37 & 3.13 & 3.63 &
\end{tabular}

${ }^{a}$ Unless otherwise noted, electron affinities (EA) and VDEs have uncertainties of \pm 50 and $\pm 25 \mathrm{meV}$, respectively.

polarization of $\theta=55^{\circ}$ with respect to the electron detection angle, the "magic angle" for which intensities are independent of the photoelectron anisotropy parameter. Spectra were obtained at other polarization angles for all clusters, but no significant effect on peak intensities was observed at $266 \mathrm{~nm}$.

The spectra directly yield vertical detachment energies (VDEs) for each neutral electronic state, using $\mathrm{VDE}=\mathrm{eBE}_{\max }$, where $\mathrm{eBE}_{\max }$ is the electron binding energy at the band maximum for the state in question. Where possible, these maxima are indicated in Figure 1 by capital letters $\mathrm{X}, \mathrm{A}, \mathrm{B}$, etc, in order of increasing VDE, and the values of the VDE's are given in Table 1. In addition, estimated adiabatic electron affinities (EA's) are listed in Table 1 and are indicated in each spectrum in Figure 1 by an arrow. The more precise EA's in 


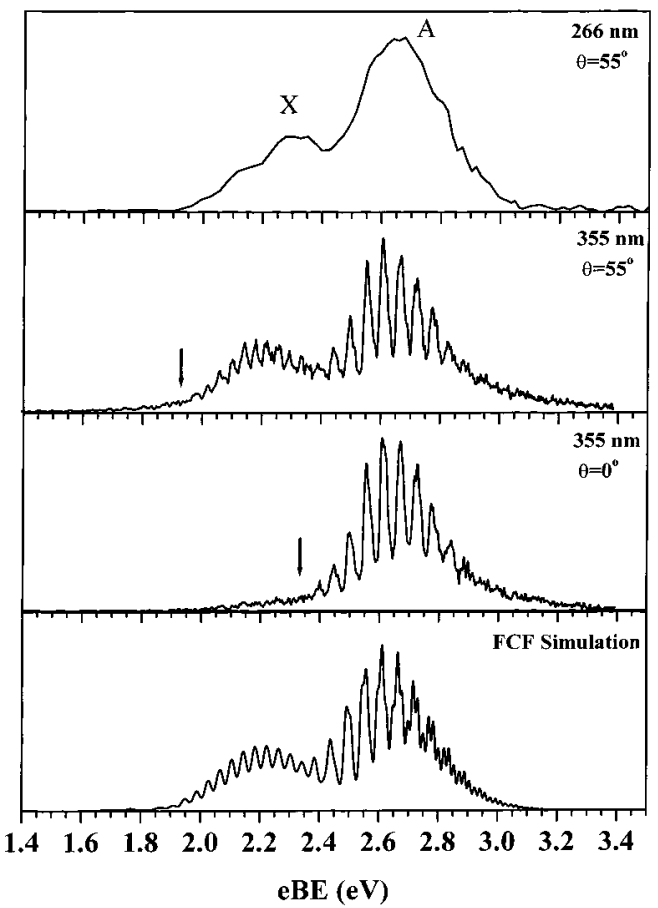

Figure 2. Photoelectron spectra of $\mathrm{AlP}_{2}{ }^{-}$clusters taken at $266 \mathrm{~nm}$ $(4.661 \mathrm{eV})$ and $355 \mathrm{~nm}(3.493 \mathrm{eV})$. Laser polarization angles are $\theta=$ $0^{\circ}$ and $\theta=55^{\circ}$ with respect to the direction of electron collection.

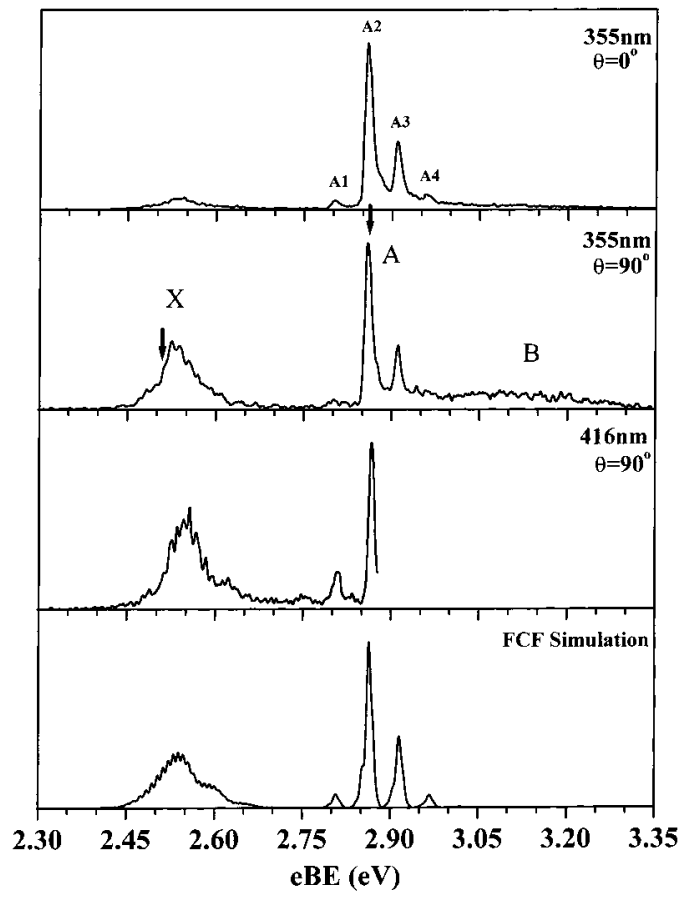

Figure 3. Photoelectron spectra of $\mathrm{Al}_{2} \mathrm{P}^{-}$clusters taken at $355 \mathrm{~nm}$ $(3.493 \mathrm{eV})$ and $416 \mathrm{~nm}(2.980 \mathrm{eV})$. Laser polarization angles are $\theta=$ $0^{\circ}$ and $\theta=90^{\circ}$ with respect to the direction of electron collection.

Table 1 are obtained from vibrationally resolved PE spectra and the determination of these values is described below. For PE spectra with no vibrational resolution, estimated EA's are taken at the point of inflection at lowest eBE. In all PE spectra, the determination of EA's is facilitated by use of the liquid nitrogen cooling channel, as this reduces the contribution of vibrationally excited anions in the spectra.

Figures 2-4 show PE spectra of $\mathrm{AlP}_{2}{ }^{-}, \mathrm{Al}_{2} \mathrm{P}^{-}$, and $\mathrm{Al}_{2} \mathrm{P}_{2}{ }^{-}$ at higher detachment wavelengths. Electrons with the same eBE are slower at these wavelengths compared to $266 \mathrm{~nm}$, so the

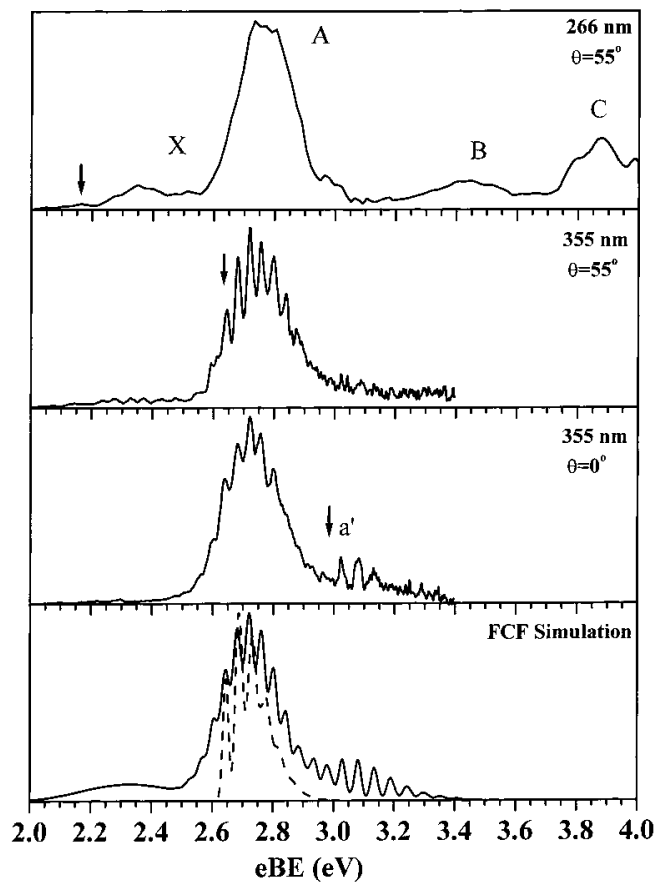

Figure 4. Photoelectron spectra of $\mathrm{Al}_{2} \mathrm{P}_{2}{ }^{-}$clusters taken at $266 \mathrm{~nm}$ $(4.661 \mathrm{eV})$ and $355 \mathrm{~nm}(3.493 \mathrm{eV})$. Laser polarization angles are $\theta=$ $0^{\circ}$ and $\theta=55^{\circ}$ with respect to the direction of electron collection.

energy resolution is higher, and more vibrational structure is resolved. In addition, we generally find a stronger dependence of the spectra on laser polarization angle than at $266 \mathrm{~nm}$; anisotropy parameters $\beta$ for each electronic band at $355 \mathrm{~nm}$ are listed in Tables $2-4$.

Figure 2 shows $\mathrm{PE}$ spectra of $\mathrm{AlP}_{2}{ }^{-}$at 266 and $355 \mathrm{~nm}$. The two spectra at $355 \mathrm{~nm}$ were taken at laser polarization angles $\theta$ $=55^{\circ}$ and $0^{\circ}$. The overall profile of the spectrum at $\theta=55^{\circ}$ is similar to that of the $266 \mathrm{~nm}$ spectrum, but band $\mathrm{X}$ is considerably less intense in the $\theta=0^{\circ}$ spectrum. The $355 \mathrm{~nm}$ spectra show clearly resolved vibrational progressions in bands $\mathrm{X}$ and $\mathrm{A}$; both bands are dominated by a single progression with vibrational frequencies of 300 and $425 \mathrm{~cm}^{-1}$, respectively.

Figure 3 shows photoelectron spectra of $\mathrm{Al}_{2} \mathrm{P}^{-}$taken at 355 $\mathrm{nm}$ with polarization angles of $\theta=0^{\circ}$ and $90^{\circ}$ and at $416 \mathrm{~nm}$ with $\theta=90^{\circ}$. Features $\mathrm{X}, \mathrm{A}$, and $\mathrm{B}$ exhibit distinctly different polarization dependences at $355 \mathrm{~nm}$. At $416 \mathrm{~nm}$, one can barely resolve a vibrational progression in band $\mathrm{X}$ with a peak spacing of $\sim 70 \mathrm{~cm}^{-1}$. Peaks $\mathrm{A} 1-\mathrm{A} 4$, associated with a transition to electronically excited $\mathrm{Al}_{2} \mathrm{P}$, show much a better resolved structure than band $\mathrm{X}$; peaks A2-A4 are spaced by $\sim 420 \mathrm{~cm}^{-1}$, while peaks A1 and A2 are spaced by $450 \mathrm{~cm}^{-1}$. There is a broad feature (B) at higher eBE.

In Figure 4, the $\mathrm{Al}_{2} \mathrm{P}_{2}{ }^{-}$photoelectron spectrum at $266 \mathrm{~nm}$ shows four peaks labeled $\mathrm{X}, \mathrm{A}, \mathrm{B}$, and $\mathrm{C}$, with peak $\mathrm{A}$ being the most intense. The $355 \mathrm{~nm}, \theta=55^{\circ}$ photoelectron spectrum shows resolved vibrational structure in band $\mathrm{A}$ with a frequency of $320 \mathrm{~cm}^{-1}$. At $\theta=0^{\circ}$, an additional resolved band $\mathrm{a}^{\prime}$ at higher eBE is seen with a characteristic peak spacing of $420 \mathrm{~cm}^{-1}$.

\section{Analysis and Discussion}

In this section, the assignment of electronic states and vibrational progressions in the PE spectra are considered. Analysis of the $\mathrm{AlP}^{-}$spectrum will be covered in a separate publication, along with spectra of related diatomic species. Here we concentrate on $\mathrm{AlP}_{2}^{-}, \mathrm{Al}_{2} \mathrm{P}^{-}$, and $\mathrm{Al}_{2} \mathrm{P}_{2}^{-}$, with some 
TABLE 2: Comparison of Geometries and Energy Separations for $\mathrm{AlP}_{2} / \mathrm{AlP}_{\mathbf{2}}{ }^{-}$

\begin{tabular}{|c|c|c|c|c|c|c|c|c|c|c|c|}
\hline reference & species & state & level & $\theta(\mathrm{deg})$ & $\mathrm{Al}-\mathrm{P}(\AA)$ & $\mathrm{P}-\mathrm{P}(\AA)$ & $\Delta E(\mathrm{eV})$ & $\omega_{1}\left(a_{1}\right)$ & $\omega_{2}\left(a_{1}\right)$ & $\omega_{3}\left(b_{2}\right)$ & $\beta_{355}$ \\
\hline \multirow[t]{4}{*}{ Feng et al. ${ }^{a}$} & $\mathrm{AlP}_{2}^{-}$ & ${ }^{1} \mathrm{~A}_{1}$ & MRSDCI+Q & 50.2 & 2.440 & 2.070 & -1.31 & & & & \\
\hline & $\mathrm{AlP}_{2}$ & ${ }^{2} \mathrm{~B}_{2}$ & & 45.0 & 2.599 & 1.989 & 0.00 & 650 & 271 & 140 & \\
\hline & $\mathrm{AlP}_{2}$ & ${ }^{2} \mathrm{~A}_{1}$ & & 56.4 & 2.268 & 2.143 & 0.63 & & & & \\
\hline & $\mathrm{AlP}_{2}$ & ${ }^{2} \mathrm{~A}_{2}$ & & 44.6 & 2.653 & 2.013 & 1.28 & & & & \\
\hline \multirow[t]{4}{*}{ archibong et al. ${ }^{b}$} & $\mathrm{AlP}_{2}^{-}$ & ${ }^{1} \mathrm{~A}_{1}$ & $\operatorname{CCSD}(\mathrm{T})$ & 50.8 & 2.422 & 2.078 & -1.92 & 578 & 378 & 304 & \\
\hline & $\mathrm{AlP}_{2}$ & ${ }^{2} \mathrm{~B}_{2}$ & B3LYP & 45.4 & 2.580 & 1.990 & 0.00 & 693 & 286 & 157 & \\
\hline & $\mathrm{AlP}_{2}$ & ${ }^{2} \mathrm{~A}_{1}$ & B3LYP & 55.6 & 2.286 & 2.132 & 0.41 & 563 & 442 & 388 & \\
\hline & $\mathrm{AlP}_{2}$ & ${ }^{2} \mathrm{~B}_{1}$ & B3LYP & 50.3 & 2.178 & 2.178 & 2.53 & 506 & 303 & 225 & \\
\hline \multicolumn{12}{|l|}{ this work } \\
\hline \multirow[t]{2}{*}{ theory } & $\mathrm{AlP}_{2}^{-}$ & ${ }^{1} \mathrm{~A}_{1}$ & $\mathrm{~B} 3 \mathrm{LYP}^{c}$ & 50.2 & 2.437 & 2.066 & -1.90 & 585 & 358 & 286 & \\
\hline & $\mathrm{AlP}_{2}$ & ${ }^{2} \mathrm{~B}_{2}$ & & 44.4 & 2.618 & 1.978 & 0.00 & 687 & 283 & 152 & \\
\hline \multirow[t]{3}{*}{ experiment } & $\mathrm{AlP}_{2}^{-}$ & ${ }^{1} \mathrm{~A}_{1}$ & PES & & & & $-1.933^{d}$ & & & & \\
\hline & $\mathrm{AlP}_{2}$ & ${ }^{2} \mathrm{~B}_{2}$ & & & & & 0.000 & & 306 & & -0.51 \\
\hline & $\mathrm{AlP}_{2}$ & ${ }^{2} \mathrm{~A}_{1}$ & & & & & 0.410 & & 425 & & 0.89 \\
\hline
\end{tabular}

${ }^{a}$ Ref 32. ${ }^{b}$ Ref $31 .{ }^{c}$ Results using DFT (B3LYP) with the aug-cc-PVTZ basis set. ${ }^{d}$ Experimental electron affinities and term energies for AlP ${ }_{2}^{-} /$ $\mathrm{AlP}_{2}$ have uncertainties of \pm 7 and $\pm 10 \mathrm{meV}$, respectively.

TABLE 3: Comparison of Geometries and Energy Separations for $\mathrm{Al}_{2} \mathbf{P} / \mathrm{Al}_{2} \mathbf{P}^{-}$

\begin{tabular}{|c|c|c|c|c|c|c|c|c|c|c|c|}
\hline reference & species & state & level & $\theta(\operatorname{deg})$ & $\mathrm{Al}-\mathrm{P}(\AA)$ & $\mathrm{Al}-\mathrm{Al}(\AA)$ & $\Delta E(\mathrm{eV})$ & $\omega_{1}\left(a_{1}\right)$ & $\omega_{2}\left(a_{1}\right)$ & $\omega_{3}\left(b_{2}\right)$ & $\beta_{355}$ \\
\hline \multirow{4}{*}{ feng et al. ${ }^{a}$} & $\mathrm{Al}_{2} \mathrm{P}^{-}$ & ${ }^{1} \mathrm{~A}_{1}$ & $\mathrm{MRSDCI}+\mathrm{Q}$ & 93.7 & 2.249 & 3.282 & -1.90 & & & & \\
\hline & $\mathrm{Al}_{2} \mathrm{P}$ & ${ }^{2} \mathrm{~B}_{2}$ & & 77.0 & 2.250 & 2.801 & 0.00 & 435 & 76 & 208 & \\
\hline & $\mathrm{Al}_{2} \mathrm{P}$ & ${ }^{2} \mathrm{~A}_{1}$ & & 106.0 & 2.304 & 3.680 & 0.43 & & & & \\
\hline & $\mathrm{Al}_{2} \mathrm{P}$ & ${ }^{2} \mathrm{~B}_{1}$ & & 114.1 & 2.378 & 3.991 & 0.58 & & & & \\
\hline \multirow{3}{*}{$\begin{array}{l}\text { this work } \\
\text { theory }\end{array}$} & & & & & & & & & & & \\
\hline & $\mathrm{Al}_{2} \mathrm{P}^{-}$ & ${ }^{1} \mathrm{~A}_{1}$ & $\mathrm{~B}^{2} \mathrm{LYP}^{b}$ & 107.7 & 2.256 & 3.644 & -2.39 & 426 & 78 & 498 & \\
\hline & $\mathrm{Al}_{2} \mathrm{P}$ & ${ }^{2} \mathrm{~B}_{2}$ & & 95.0 & 2.243 & 3.307 & 0.00 & 430 & 69 & 230 & \\
\hline \multirow[t]{4}{*}{ experiment } & $\mathrm{Al}_{2} \mathrm{P}^{-}$ & ${ }^{1} \mathrm{~A}_{1}$ & PES & & & & $-2.513^{c}$ & 450 & & & \\
\hline & $\mathrm{Al}_{2} \mathrm{P}$ & ${ }^{2} \mathrm{~B}_{2}$ & & & & & 0.000 & & $\sim 70$ & & -0.95 \\
\hline & $\mathrm{Al}_{2} \mathrm{P}$ & ${ }^{2} \mathrm{~A}_{1}$ & & & & & 0.346 & 421 & & & -0.05 \\
\hline & $\mathrm{Al}_{2} \mathrm{P}$ & ${ }^{2} \mathrm{~B}_{1}$ & & & & & 0.5 & & & & \\
\hline
\end{tabular}

${ }^{a}$ Ref $32 .{ }^{b}$ Results using DFT (B3LYP) with the aug-cc-PVTZ basis set. ${ }^{c}$ Experimental electron affinities and term energies for $\mathrm{Al}_{2} \mathrm{P}^{-} / \mathrm{Al}_{2} \mathrm{P}$ have uncertainties of $\pm 20 \mathrm{meV}$ and $\pm 23 \mathrm{meV}$, respectively.

TABLE 4: Comparparison of Geometries and Energy Separations for $\mathbf{A l}_{2} \mathbf{P}_{2} / \mathbf{A l}_{2} \mathbf{P}_{2}-$

\begin{tabular}{|c|c|c|c|c|c|c|c|c|c|c|c|}
\hline reference & specie & state & & level & $\begin{array}{l}\theta \text { (deg) } \\
\text { (PAlP) }\end{array}$ & $\begin{array}{c}\mathrm{Al}-\mathrm{P} \\
(\AA)\end{array}$ & $\begin{array}{l}\mathrm{P}-\mathrm{P} \\
(\AA)\end{array}$ & $\begin{array}{c}\varphi \\
\text { (AlPPAl) }\end{array}$ & $\begin{array}{c}\Delta E \\
(\mathrm{eV})\end{array}$ & $\begin{array}{l}\text { frequencies } \\
v_{\mathrm{a}}\left(\mathrm{cm}^{-1}\right)\end{array}$ & $\beta_{355}$ \\
\hline \multirow{2}{*}{ feng et al. ${ }^{a}$} & $\mathrm{Al}_{2} \mathrm{P}_{2}^{-}$ & ${ }^{2} \mathrm{~B}_{1 \mathrm{~g}}$ & $D_{2 h}$ & MRSDCI+Q & 55.3 & 2.417 & 2.242 & 180 & -1.33 & & \\
\hline & $\mathrm{Al}_{2} \mathrm{P}_{2}$ & ${ }^{1} \mathrm{~A}_{\mathrm{g}}$ & $D_{2 h}$ & & 49.2 & 2.521 & 2.100 & 180 & 0.00 & & \\
\hline \multirow[t]{4}{*}{ archibong et al. ${ }^{b}$} & $\mathrm{Al}_{2} \mathrm{P}_{2}^{-}$ & ${ }^{2} \mathrm{~B}_{1}$ & $C_{2 v}$ & B3LYP & 54.3 & 2.434 & 2.222 & 148 & -1.83 & $\begin{array}{l}468,307,74\left(\mathrm{a}_{1}\right), \\
312\left(\mathrm{a}_{2}\right), 395\left(b_{1}\right), \\
193\left(\mathrm{~b}_{2}\right)\end{array}$ & \\
\hline & $\mathrm{Al}_{2} \mathrm{P}_{2}$ & ${ }^{1} \mathrm{~A}_{\mathrm{g}}$ & $D_{2 h}$ & & 48.5 & 2.529 & 2.067 & 180 & 0.00 & $\begin{array}{l}588,274\left(\mathrm{a}_{\mathrm{g}}\right) \\
276\left(\mathrm{~b}_{3 \mathrm{~g}}\right), 340\left(\mathrm{~b}_{1 \mathrm{u}}\right) \\
159\left(\mathrm{~b}_{2 \mathrm{u}}\right), 88\left(\mathrm{~b}_{3 \mathrm{u}}\right)\end{array}$ & \\
\hline & $\mathrm{Al}_{2} \mathrm{P}_{2}$ & ${ }^{3} \mathrm{~A}_{2}$ & $C_{2 v}$ & & 59.0 & 2.366 & 2.331 & 159 & 0.70 & $\begin{array}{l}440,314,59\left(\mathrm{a}_{1}\right) \\
312\left(\mathrm{a}_{2}\right), 239\left(\mathrm{~b}_{1}\right) \\
328\left(\mathrm{~b}_{2}\right)\end{array}$ & \\
\hline & $\mathrm{Al}_{2} \mathrm{P}_{2}$ & ${ }^{3} \mathrm{~B}_{2}$ & $C_{2 v}$ & & 47.1 & 2.610 & 2.085 & 115 & 1.08 & $\begin{array}{l}563,266,83\left(\mathrm{a}_{1}\right) \\
37\left(\mathrm{a}_{2}\right), 109\left(\mathrm{~b}_{1}\right) \\
289\left(\mathrm{~b}_{2}\right)\end{array}$ & \\
\hline \multirow{4}{*}{$\begin{array}{l}\text { this work } \\
\text { theory }\end{array}$} & $\mathrm{Al}_{2} \mathrm{P}_{2}^{-}$ & ${ }^{2} \mathrm{~B}_{1}$ & $C_{2 v}$ & B3LYP & 54.4 & 2.440 & 2.231 & 149 & -1.87 & $\begin{array}{l}475,304,67\left(a_{1}\right) \\
241\left(a_{2}\right)\end{array}$ & \\
\hline & & & & & & & & & & $395\left(b_{1}\right), 193\left(b_{2}\right)$ & \\
\hline & $\mathrm{Al}_{2} \mathrm{P}_{2}$ & ${ }^{1} \mathrm{~A}_{\mathrm{g}}$ & $D_{2 h}$ & & 48.3 & 2.536 & 2.073 & 180 & 0.00 & $\begin{array}{l}585,274\left(\mathrm{a}_{\mathrm{g}}\right) \\
275\left(\mathrm{~b}_{3 \mathrm{~g}}\right) \\
339\left(\mathrm{~b}_{1 \mathrm{u}}\right), 158\left(\mathrm{~b}_{2 \mathrm{u}}\right) \\
87\left(\mathrm{~b}_{3 \mathrm{u}}\right)\end{array}$ & \\
\hline & $\mathrm{Al}_{2} \mathrm{P}_{2}$ & ${ }^{3} \mathrm{~A}_{2}$ & $C_{2 v}$ & & 59.5 & 2.370 & 2.341 & 160 & 0.60 & $\begin{array}{l}437,312,55\left(\mathrm{a}_{1}\right) \\
309\left(\mathrm{a}_{2}\right) \\
327\left(\mathrm{~b}_{1}\right), 235\left(\mathrm{~b}_{2}\right)\end{array}$ & \\
\hline \multirow[t]{4}{*}{ experiment } & $\mathrm{Al}_{2} \mathrm{P}_{2}^{-}$ & ${ }^{2} \mathrm{~B}_{1}$ & $C_{2 v}$ & PES & & & & & $-2.15^{c}$ & & \\
\hline & $\mathrm{Al}_{2} \mathrm{P}_{2}$ & ${ }^{1} \mathrm{~A}_{\mathrm{g}}$ & $D_{2 h}$ & & & & & & 0.000 & & $\sim-0.1$ \\
\hline & $\mathrm{Al}_{2} \mathrm{P}_{2}$ & ${ }^{3} \mathrm{~A}_{2}^{0}$ & $C_{2 v}$ & & & & & & 0.493 & 320 & 0.38 \\
\hline & $\mathrm{Al}_{2} \mathrm{P}_{2}$ & ${ }^{3} \mathrm{~B}_{2}^{d}$ & $C_{2 v}$ & & & & & & 0.846 & 420 & 0.57 \\
\hline
\end{tabular}

${ }^{a}$ Ref 30. ${ }^{b}$ Ref 31. ${ }^{c}$ Experimental electron affinities and term energies for $\mathrm{Al}_{2} \mathrm{P}_{2}-/ \mathrm{Al}_{2} \mathrm{P}_{2}$ have an uncertainty of \pm 100 meV. ${ }^{d}$ Tentative assignment.

discussion of the larger clusters at the end of this section. In addition, the $\mathrm{Al}_{x} \mathrm{P}_{y}{ }^{-} \mathrm{PE}$ spectra are compared to previously results on $\mathrm{Ga}_{x} \mathrm{P}_{y}{ }^{-}$and $\mathrm{In}_{x} \mathrm{P}_{y}{ }^{-}$clusters.
Assignment of the $\mathrm{Al}_{x} \mathrm{P}_{y}{ }^{-}$spectra is facilitated by comparison with the electronic structure calculations of Archibong et al. ${ }^{31}$ and Feng and Balasubramanian ${ }^{29,30,32}$ These calculations report 
TABLE 5: Photoelectron Spectra Simulation Parameters for Active Modes in $\mathbf{A l}_{2} \mathbf{P}^{-}, \mathrm{AlP}_{2}{ }^{-}$, and $\mathbf{A l}_{2} \mathbf{P}_{2}^{-}$

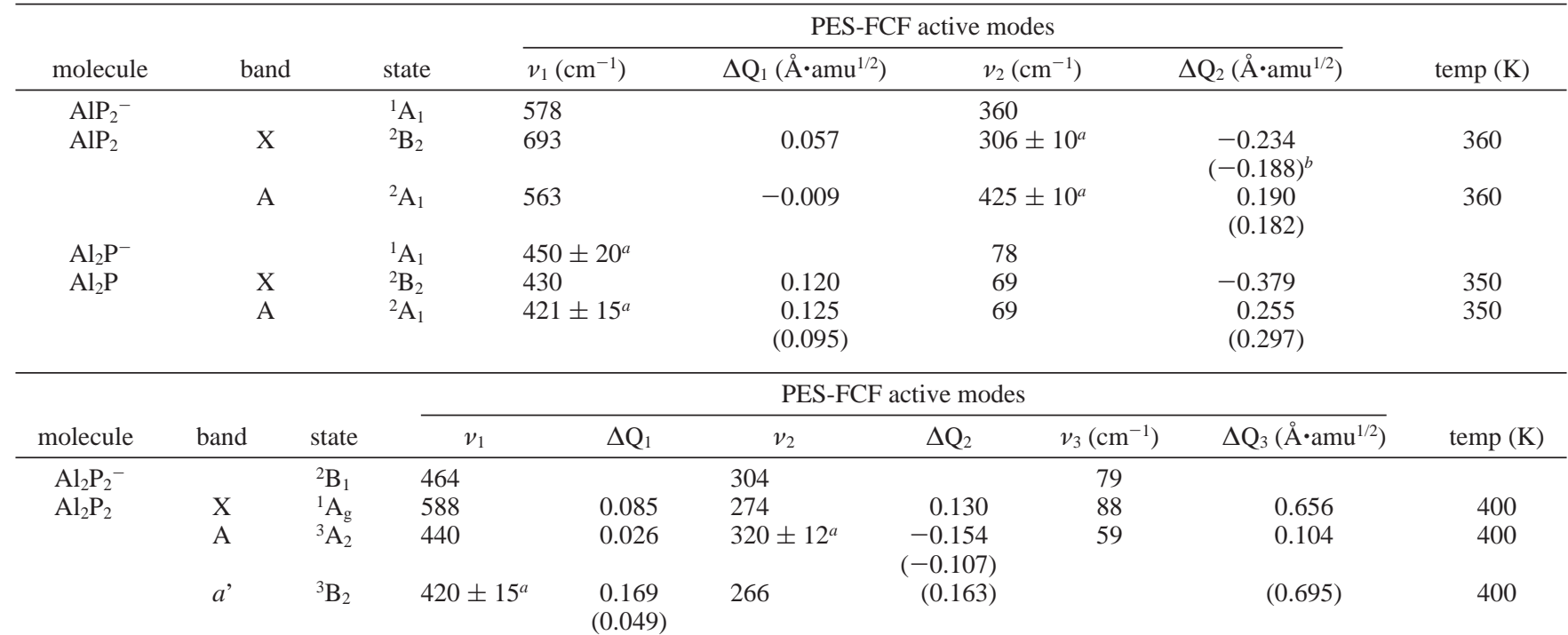

${ }^{a}$ Observed experimental progression. ${ }^{b}$ Normal coordinate displacements from electronic structure calculations are included in parentheses if different from simulation parameters.

electronic state energies, geometries, and vibrational frequencies for several $\mathrm{Al}_{x} \mathrm{P}_{y}$ neutral and charged clusters. Results at the highest level of theory reported by each group are listed in Tables 2-4 for $\mathrm{AlP}_{2}, \mathrm{Al}_{2} \mathrm{P}$, and $\mathrm{Al}_{2} \mathrm{P}_{2}$. While we can directly compare our experimental band origins and vibrational frequencies to these calculations, it is also valuable to simulate the PE spectra within the Franck-Condon approximation in order to determine how well the calculated changes in geometry upon photodetachment compare to experiment. These simulations are best done using normal coordinates determined from ab initio force constants for the anion and neutral, and since these values are typically not reported, we have performed our own ab initio calculations on several anion and neutral clusters both as a check on previous reports and to generate a set of force constants with which to simulate the PE spectrum. These calculations were performed on anionic and neutral ground states of $\mathrm{AlP}_{2}, \mathrm{Al}_{2} \mathrm{P}$, and $\mathrm{Al}_{2} \mathrm{P}_{2}$ using the GAUSSIAN98 ${ }^{37}$ program package. The correlation-consistent polarized valence basis sets of Dunning and co-workers, ${ }^{38}$ denoted by cc-pV $x \mathrm{Z}$ where, $x=\mathrm{D}$ (double$\zeta$ ) and $\mathrm{T}$ (triple- $\zeta$ ), were used for the neutral species. Additional diffuse functions are especially important for the description of molecular ions, and we therefore mostly used augmented correlation consistent sets of Kendall et al., ${ }^{39}$ denoted by augcc-pVxZ $(x=\mathrm{D}, \mathrm{T})$. The geometries and vibrational frequencies were determined using density functional theory (DFT) with the B3LYP (Becke-3-parameter-Lee-Yang-Parr) exchange correlation functional. ${ }^{40,41}$ Results from our calculations are also listed in Tables 2-4.

Franck-Condon simulations were calculated within the parallel mode approximation. Using the anion and neutral geometries from the electronic structure calculations and the negative ion normal coordinates, we determined the normal mode displacements between the anion and various neutral electronic states for each cluster. These displacements and the calculated anion and neutral frequencies served as the starting point in the simulations and were then modified in order to best reproduce the experimental PE spectra. The anion vibrational temperature was also varied in order to reproduce hot bands in the spectrum originating from vibrationally excited anions. The resulting stick spectrum was then convoluted with a Gaussian function of width comparable to our experimental resolution, usually $8-15 \mathrm{meV}$. The simulations provide a detailed com- parison with theory and also aid in determining the vibrational origin of electronic bands in which the origin is not obvious by inspection.

Simulation parameters for the $\mathrm{AlP}_{2}{ }^{-}, \mathrm{Al}_{2} \mathrm{P}^{-}$, and $\mathrm{Al}_{2} \mathrm{P}_{2}^{-}$ spectra are listed in Table 5. Because several of the vibrational progressions are quite extended, we can obtain vibrational frequencies with higher accuracy than our experimental resolution; error bars for the vibrational frequencies (see Table 5) are as low as $10 \mathrm{~cm}^{-1}$. In addition, for well-resolved bands, the error in determining the vibrational origin of a particular band is no larger than \pm 1 quantum in the most active neutral vibrational frequency.

A. $\mathbf{A l P}_{2}$. Electronic structure calculations by Feng and Balasubramanian ${ }^{32}$ and Archibong et al. ${ }^{31}$ find that $\mathrm{AlP}_{2}{ }^{-}$has a ${ }^{1} \mathrm{~A}_{1}$ ground state, while $\mathrm{AlP}_{2}$ has a $\tilde{X}^{2} \mathrm{~B}_{2}$ ground state and low-lying $\tilde{A}{ }^{2} \mathrm{~A}_{1}$ excited state. The geometries are similar for all calculations listed in Table 2 and show $\mathrm{AlP}_{2}$ and $\mathrm{AlP}_{2}{ }^{-}$to be acute triangles, with $\angle \mathrm{P}-\mathrm{Al}-\mathrm{P}$ ranging from $45-56^{\circ}$, indicating strong $\mathrm{P}-\mathrm{P}$ bonding in all cases. Archibong notes that the B3LYP results for the $\mathrm{P}-\mathrm{P}$ bond length and frequency in the $\mathrm{AlP}_{2}$ ground state are closer to the respective values for $\mathrm{P}_{2}^{-}$than for neutral $\mathrm{P}_{2}$, a result consistent with the Mulliken population analysis by Feng showing net negative charge on the $\mathrm{P}$ atoms. Feng calculates a lower EA (1.31 vs $1.92 \mathrm{eV})$ and larger $\tilde{X}-\tilde{A}$ splitting $(0.63$ vs $0.41 \mathrm{eV})$ than Archibong. The $v_{1}$, $v_{2}$, and $v_{3}$ vibrational modes correspond respectively to $\mathrm{P}-\mathrm{P}$ stretching, Al-P stretching, and an antisymmetric stretch mode, which is inactive in the photoelectron spectrum since the relevant anion and neutral electronic states all have $C_{2 v}$ symmetry.

Turning to the $\mathrm{AlP}_{2}{ }^{-}$spectra in Figure 2, it appears by inspection that the origin of band $\mathrm{X}$ is at $\mathrm{eBE} \cong 2.0 \mathrm{eV}$ and that the VDE's of bands $\mathrm{X}$ and A differ by about $0.4 \mathrm{eV}$. These energetics agree well with those calculated by Archibong, assuming band $\mathrm{X}$ and $\mathrm{A}$ correspond to transitions to the $\tilde{X}^{2} \mathrm{~B}_{2}$ and $\tilde{A}{ }^{2} \mathrm{~A}_{1}$ states of $\mathrm{AlP}_{2}$, respectively. On the basis of Archibong's anion and neutral geometries and our anion force constants and normal coordinates, we find $\Delta Q_{1}=0.057 \AA$ $\mathrm{amu}^{1 / 2}$ and $\Delta Q_{2}=-0.188 \AA \mathrm{amu} u^{1 / 2}$ for detachment to the $\tilde{X}$ ${ }^{2} \mathrm{~B}_{2}$ state and $\Delta Q_{1}=-0.009 \AA \mathrm{amu}{ }^{1 / 2}$ and $\Delta Q_{2}=0.182 \AA$ $\mathrm{amu}^{1 / 2}$ for detachment to the $\tilde{A}{ }^{2} \mathrm{~A}_{1}$ state. Hence, for both transitions, nearly all the FC activity is in the $v_{2}$ mode, at least within the parallel mode approximation. The normal coordinate 
TABLE 6: Neutral Structures Based on Best-Fit Normal Coordinate Displacements Using Calculated Anion Geometries as References

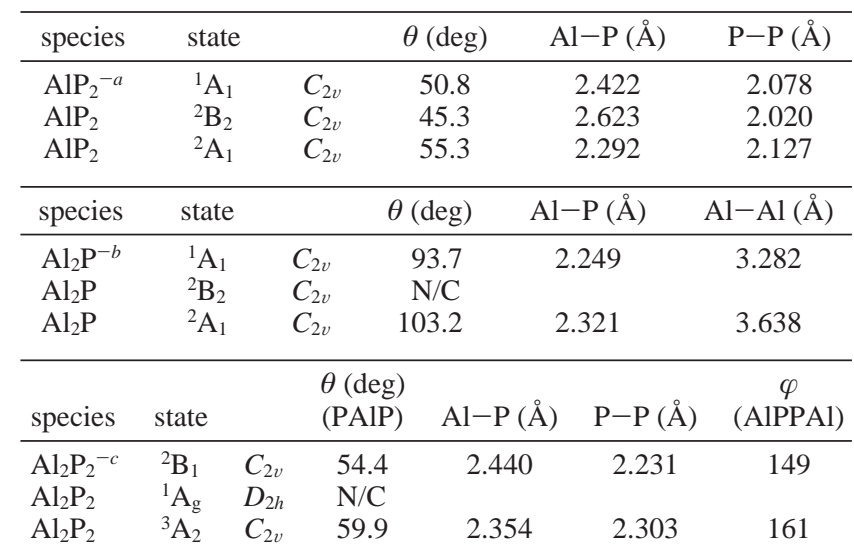

${ }^{a}$ Anion geometry from ref $31 .{ }^{b}$ Anion geometry from ref $32 .{ }^{c}$ Anion geometry from ref 31 .

displacements and anisotropy parameters (Table 2) reflect the different characters of the molecular orbitals from which detachment occurs. As pointed out by Archibong, ${ }^{31}$ the $7 b_{2}$ orbital is $\mathrm{P}-\mathrm{P}$ antibonding and $\mathrm{Al}-\mathrm{P}$ bonding, whereas the $11 \mathrm{a}_{1}$ orbital is $\mathrm{P}-\mathrm{P}$ bonding.

Figure 2 (bottom) shows the best-fit simulation to the $\mathrm{AlP}_{2}{ }^{-}$ PE spectrum, obtained using the parameters in Table 5. There is generally good agreement between the simulation parameters and the electronic structure parameters calculated by Archibong, the main difference being that $\Delta Q_{2}$ needed to be decreased to $-0.234 \AA$ amu ${ }^{1 / 2}$ to reproduce the $\tilde{X}^{2} \mathrm{~B}_{2}$ band; we assume that the sign of the normal coordinate displacement is the same as that in the electronic structure calculations. Using Archibong's calculated anion geometry as a reference, we can obtain the neutral geometries using the best fit normal coordinate displacements. These are given in Table 6; comparison with Table 2 shows a larger increase in $\mathrm{Al}-\mathrm{P}$ bond length and a larger decrease in the $\mathrm{P}-\mathrm{P}$ bond length for detachment to the $\tilde{X}^{2} \mathrm{~B}_{2}$ state than those predicted by the calculations.

B. $\mathbf{A l}_{\mathbf{2}} \mathbf{P}$. The calculations by Feng and Balusubramanian ${ }^{32}$ on $\mathrm{Al}_{2} \mathrm{P}^{-}$and $\mathrm{Al}_{2} \mathrm{P}$ show a strong dependence on the level of theory, particularly for the anion and some of the neutral excited states. At the highest level (MRSDCI $+\mathrm{Q}), \mathrm{Al}_{2} \mathrm{P}^{-}$has a ${ }^{1} \mathrm{~A}_{1}$ ground state lying $1.90 \mathrm{eV}$ below the neutral ${ }^{2} \mathrm{~B}_{2}$ ground state, while the ${ }^{2} \mathrm{~A}_{1}$ and ${ }^{2} \mathrm{~B}_{1}$ excited states are calculated to lie 0.43 and $0.58 \mathrm{eV}$, respectively, above the neutral ground state. At the DFT(B3LYP) level of theory, the calculated ${ }^{32}$ symmetric stretch and bend frequencies for the ground state are $v_{1}=435$ $\mathrm{cm}^{-1}$ and $v_{2}=76 \mathrm{~cm}^{-1}$; the lower-frequency mode approximately matches the spacing in band $X$ of the $416 \mathrm{~nm}$ experimental spectrum in Figure 3.

The normal coordinate displacements analysis for $\mathrm{Al}_{2} \mathrm{P} / \mathrm{Al}_{2} \mathrm{P}^{-}$ were determined using our calculated force constants at the DFT level of theory and the MRSDCI+Q geometries from Feng in Table 3. The calculated $\angle \mathrm{Al}-\mathrm{P}-\mathrm{Al}$ bend angle changes significantly upon photodetachment to the ground state, from $93.7^{\circ}$ to $77^{\circ}$. We expect an extended bend progression in the PE spectrum, similar to what was seen in the ZEKE spectrum of $\mathrm{InP}_{2}{ }^{-}$by Arnold et al. ${ }^{14} \mathrm{On}$ the basis of the calculations, the normal coordinate displacements are $\Delta Q_{1}=0.120 \AA \mathrm{amu}^{1 / 2}$ and $\Delta \mathrm{Q}_{2}=-0.379 \AA \mathrm{amu}^{1 / 2}$ for detachment to the $\tilde{X}^{2} \mathrm{~B}_{2}$ state, so some activity in the $v_{1}$ mode is expected as well. A FranckCondon simulation using these values is shown in Figure 3 (bottom) and is quite similar in appearance to the experimental band $\mathrm{X}$, confirming the assignment of band $\mathrm{X}$ to the ${ }^{2} \mathrm{~B}_{2} \leftarrow{ }^{1} \mathrm{~A}_{1}$ photodetachment transition. From the shape of band $\mathrm{X}$, we estimate a vibrational origin and adiabatic electron affinity of $2.513 \pm 0.020 \mathrm{eV}$.

The progression $\mathrm{A} 1-\mathrm{A} 4$ could correspond to either of the two close-lying excited states in Table 3. To distinguish these, we note that at the MRSDCI+Q level of theory, the calculated bend angles for the ${ }^{2} \mathrm{~A}_{1}$ and ${ }^{2} \mathrm{~B}_{1}$ states are $106.0^{\circ}$ and $114.1^{\circ}$, respectively, and that the ${ }^{2} \mathrm{~A}_{1}$ angle is considerably closer to the calculated angle in the anion. The relatively narrow peaks A1-A4 are therefore more likely to result from a transition to the ${ }^{2} \mathrm{~A}_{1}$ state than to the ${ }^{2} \mathrm{~B}_{1}$ state. These peaks were simulated in Figure 3 using the parameters in Table 5. Using Feng's anion geometry as a reference, we give the neutral geometry in Table 6 . It is quite close to Feng's calculated ${ }^{2} \mathrm{~A}_{1}$ state geometry (Table 3 ), supporting our assignment of this band to the ${ }^{2} \mathrm{~A}_{1} \leftarrow{ }^{1} \mathrm{~A}_{1}$ transition.

The simulations yield frequencies of 450 and $421 \mathrm{~cm}^{-1}$ for the anion and neutral, respectively, assigning A2 as the origin and A1 as a hot band. By analogy to the ground state, this frequency is assigned to the symmetric stretch. The peak widths result from relatively short, unresolved bend progressions. The adiabatic detachment energy (ADE) to the ${ }^{2} \mathrm{~A}_{1}$ state is $2.859 \pm 0.007 \mathrm{eV}$, while the term value for the ${ }^{2} \mathrm{~A}_{1}$ state is $0.346 \pm 0.023 \mathrm{eV}$, in reasonable agreement with the calculated value; the larger error bar in the term value reflects the uncertainty in the vibrational origin of band $\mathrm{X}$. We assign the broad band $\mathrm{B}$ to the ${ }^{2} \mathrm{~B}_{1}$ state, with a very approximate term value of $0.5 \mathrm{eV}$.

C. $\mathbf{A l}_{2} \mathbf{P}_{2}$. The PE spectrum of $\mathrm{Al}_{2} \mathrm{P}_{2}{ }^{-}$at $266 \mathrm{~nm}$ shows transitions to at least four electronic states, labeled $\mathrm{X}, \mathrm{A}, \mathrm{B}$, and $\mathrm{C}$ in the top panel of Figure 4. At $355 \mathrm{~nm}$, where the electron energy resolution is higher for the same eBE, band $\mathrm{X}$ shows no vibrational structure, but band $\mathrm{A}$ shows a resolved progression with frequency $320 \mathrm{~cm}^{-1}$. These observations suggest a larger geometry change upon photodetachment to the ground state of $\mathrm{Al}_{2} \mathrm{P}_{2}$ than to its first excited state. This interpretation is consistent with the ab initio calculations of Archibong et al., ${ }^{31}$ in which the anion is found to have a nonplanar ${ }^{2} \mathrm{~B}_{1}$ ground state of $C_{2 v}$ symmetry, whereas $\mathrm{Al}_{2} \mathrm{P}_{2}$ has a ${ }^{1} \mathrm{~A}_{\mathrm{g}}$ planar rhombus $\left(D_{2 h}\right)$ ground state and a low-lying ${ }^{3} \mathrm{~A}_{2}$ excited state with the same symmetry as the anion.

FC simulations provide a more quantitative interpretation of the PE spectra. The solid line in the bottom panel of Figure 4 shows a simulated spectrum incorporating transitions to three $\mathrm{Al}_{2} \mathrm{P}_{2}$ electronic states, and the three components of the simulation were determined as follows. On the basis of Archibong's geometries and frequencies and our force constants, the normal coordinates displacement for photodetachment to the $\mathrm{Al}_{2} \mathrm{P}_{2}$ ground state are given in Table 5. These displacements should result in a very long progression in the low-frequency $\left(v_{3}=88 \mathrm{~cm}^{-1}\right)$ breathing mode of $\mathrm{Al}_{2} \mathrm{P}_{2}$ upon photodetachment, as well as modest excitation in the symmetric $\mathrm{P}-\mathrm{P}\left(\nu_{1}\right)$ and $\mathrm{Al}-\mathrm{P}\left(v_{2}\right)$ stretches. Note that all three modes are totally symmetric in the lower symmetry $C_{2 v}$ point group, the appropriate group to use when the symmetry changes upon photodetachment. Simulation of the ground-state band using Archibong's geometries and an electron affinity of $2.15 \pm 0.10 \mathrm{eV}$ yields an unstructured band that extends from 1.9 to $2.7 \mathrm{eV}$. With appropriate scaling, the simulation of this band resembles band $\mathrm{X}$ in our spectra, as can be seen from the low eBE portion of the simulated spectrum in Figure 4. The low intensity of band $\mathrm{X}$ probably results from a combination of being spread out over a large electron energy range and a low photodetachment cross section. 
Photodetachment to the ${ }^{3} \mathrm{~A}_{2}$ excited state also results in activity in the three totally symmetric modes, but there is considerably less activity in the $v_{3}$ mode. The dotted line in the bottom panel of Figure 4 shows an FC simulation of this transition on the basis of Archibong's geometries; it is dominated by a progression in the $v_{2}$ mode with a calculated frequency of $314 \mathrm{~cm}^{-1}$. This progression resembles the experimental band A but is too short. Better agreement (solid line, Figure 4, bottom) is obtained by decreasing $\Delta Q_{2}$ from -0.107 to $-0.154 \AA \mathrm{amu}^{1 / 2}$ and increasing the $v_{2}$ frequency slightly to $320 \mathrm{~cm}^{-1}$; the other $\Delta Q$ values are given in Table 5. Using Archibong's calculated anion geometry as a reference, we give the ${ }^{3} \mathrm{~A}_{2}$ geometry resulting from the best-fit normal coordinate displacements in Table 6 , and these are quite close to the calculated ${ }^{3} \mathrm{~A}_{2}$ geometries in Table 4. The simulation yields the adiabatic detachment energy for band A of $2.643 \pm 0.010 \mathrm{eV}$, resulting in a term value of $0.49 \pm 0.10 \mathrm{eV}$ for the ${ }^{3} \mathrm{~A}_{2}$ state, slightly lower than the calculated value in Table 4.

Band $\mathrm{a}^{\prime}$ in the $\mathrm{Al}_{2} \mathrm{P}_{2}{ }^{-}$photoelectron spectra shows a short progression of peaks spaced by $420 \mathrm{~cm}^{-1}$. In the bottom panel of Figure 4, this band is simulated assuming a single active mode with $\Delta Q=0.169 \AA \mathrm{amu}^{1 / 2}$ and a term value of 0.846 $\mathrm{eV}$. This state lies close to the calculated term value for the ${ }^{3} \mathrm{~B}_{2}$ excited state, but the calculated frequencies of 563 and $266 \mathrm{~cm}^{-1}$ for the $v_{1}$ and $v_{2}$ modes do not agree well with the experimental peak spacing. Also, on the basis of the calculated geometry in Table 4, there should be more than one active normal mode; the normal coordinate displacements are $\Delta Q_{1}=0.045 \AA \mathrm{amu}^{1 / 2}$, $\Delta Q_{2}=0.163 \AA \mathrm{amu}^{1 / 2}$, and $\Delta Q_{3}=0.695 \AA \mathrm{amu}^{1 / 2}$. These are similar to the displacements for detachment to the ground state, so one expects a broad, unresolved band dominated by a progression in the low frequency $v_{3}$ mode. We tentatively assign band $\mathrm{a}^{\prime}$ to the ${ }^{3} \mathrm{~B}_{2}$ electronic state on the basis of the calculated energetics, but is clear that the calculated structure and frequencies do not agree with experiment.

D. Other Clusters. The spectra for the other four atom clusters in Figure $1, \mathrm{AlP}_{3}^{-}$and $\mathrm{Al}_{3} \mathrm{P}^{-}$, can be tentatively assigned by comparison with electronic structure calculations by Feng and Balasubramanian, ${ }^{29}$ in which the energies and geometries of the neutral ground and excited states were calculated at the CASSCF and MRSDCI levels of theory. The calculations predict that $\mathrm{AlP}_{3}$ and $\mathrm{Al}_{3} \mathrm{P}$ have ${ }^{3} \mathrm{~A}_{2}$ and ${ }^{1} \mathrm{~A}_{1}$ ground states, respectively, both with $C_{3 v}$ symmetry. $\mathrm{AlP}_{3}$ has closelying ${ }^{3} \mathrm{E}$ and ${ }^{1} \mathrm{E}$ excited states lying 0.31 and 0.40 above the ground state, both of which presumably undergo Jahn-Teller distortion. The PE spectrum of $\mathrm{AlP}_{3}{ }^{-}$is comprised of three bands; the VDE's of band A and B are 0.28 and $0.64 \mathrm{eV}$ higher than the VDE of band $\mathrm{X}$. These energies suggest assigning band $\mathrm{X}$ to the ${ }^{3} \mathrm{~A}_{2}$ ground state, band $\mathrm{A}$ to the overlapped ${ }^{3} \mathrm{E}$ and ${ }^{1} \mathrm{E}$ states, and band $\mathrm{B}$ to a higher-lying state not considered in the calculation.

The $\mathrm{Al}_{3} \mathrm{P}^{-}$photoelectron spectrum also has three distinctive peaks that are narrower and considerably better separated than in the $\mathrm{AlP}_{3}{ }^{-}$spectrum. Band $\mathrm{X}$ shows partially resolved peaks separated by $340 \mathrm{~cm}^{-1}$, and from the apparent origin of this band, we obtain an EA of $2.051 \pm 0.020 \mathrm{eV}$. On the basis of the differences in the VDEs, peaks $\mathrm{X}$ and $\mathrm{A}$ are separated by $0.87 \mathrm{eV}$, while peaks $\mathrm{X}$ and $\mathrm{B}$ are separated by $1.30 \mathrm{eV}$. The large gap between electronic states qualitatively agrees with electronic structure calculations on $\mathrm{Al}_{3} \mathrm{P}$, which predict two lowlying electronic states, ${ }^{3} \mathrm{E}$ and ${ }^{1} \mathrm{~A}_{2}$, also with $C_{3 v}$ symmetry, to lie 1.86 and $2.46 \mathrm{eV}$, respectively, above the ground state. However, the calculated excitation energies are clearly larger that in the experimental spectrum.
Consideration of the molecular orbital configurations presented by Feng and Balasubramanian suggests that $\mathrm{AlP}_{3}{ }^{-}$and $\mathrm{Al}_{3} \mathrm{P}^{-}$both have ${ }^{2} \mathrm{E}$ ground states. The widths of band $\mathrm{X}$ in the PE spectra indicate a much larger geometry change upon photodetachment to the neutral ground state for $\mathrm{AlP}_{3}{ }^{-}$than that for $\mathrm{Al}_{3} \mathrm{P}^{-}$, possibly indicating more substantial Jahn-Teller distortion in $\mathrm{AlP}_{3}{ }^{-}$. To date, no calculations have been performed on either anion.

The $\mathrm{Al}_{2} \mathrm{P}_{3}-\mathrm{PE}$ spectrum is dominated by a single sharp band $(\mathrm{X})$ which shows partially resolved vibrational structure with a separation of approximately $465 \mathrm{~cm}^{-1}$. It is of interest to compare this to the PE spectra of $\mathrm{Ga}_{2} \mathrm{P}_{3}{ }^{-}$and $\mathrm{Ga}_{2} \mathrm{As}_{3}{ }^{-42,43}$ both of which show better-resolved vibrational structures with a lower vibrational frequency (220 and $200 \mathrm{~cm}^{-1}$, respectively). The PE spectra of $\mathrm{Ga}_{2} \mathrm{P}_{3}{ }^{-}$and $\mathrm{Ga}_{2} \mathrm{As}_{3}{ }^{-}$result from transitions between two trigonal bipyrimidal structures, and the progression corresponds to stretching of the axial $\mathrm{Ga}$ atoms. Preliminary calculations on $\mathrm{Al}_{2} \mathrm{P}_{3}$ suggest that the considerably higher frequency in the $\mathrm{Al}_{2} \mathrm{P}_{3}-\mathrm{PE}$ spectrum is an equatorial $\mathrm{P}-\mathrm{P}$ symmetric stretch. The more poorly resolved structure relative to the Ga-containing clusters may result from additional FC activity in the lower-frequency $\mathrm{Al}-\mathrm{Al}$ axial stretch or from a lowering of symmetry in the neutral resulting in even more modes becoming active.

The $\mathrm{Al}_{3} \mathrm{P}_{3}{ }^{-} \mathrm{PE}$ spectrum (Figure 1) is the only other spectrum for which vibrational structure is resolved; band $\mathrm{X}$ shows a partially resolved progression with a peaks spacing of $630 \mathrm{~cm}^{-1}$, and on the basis of the apparent origin of this progression, the EA of $\mathrm{Al}_{3} \mathrm{P}_{3}$ is $2.450 \pm 0.020 \mathrm{eV}$. Band $\mathrm{X}$ is well-separated from band A, with their VDE's differing by $1.18 \mathrm{eV}$. Raghavachari and co-workers ${ }^{26}$ performed an extensive search for the ground-state geometry of $\mathrm{Al}_{3} \mathrm{P}_{3}$ in an electronic structure calculation. At the highest level of theory applied (QCISD(T)), this structure was found to be an Al-capped trigonal bipyramid with $C_{S}$ symmetry. A similar result was found by Ramakrishna ${ }^{28}$ in a more recent calculation using DFT within the local density approximation (LDA).

While it is difficult to say anything definitive about the $\mathrm{Al}_{3} \mathrm{P}_{3}$ structure from the experimental PE spectrum, the narrow width of band $\mathrm{X}(280 \mathrm{meV})$ and the fact that we can observe any vibrational structure in a cluster of this size suggests that the geometries of the negative ion and neutral are similar. Raghavachari also calculated vibrational frequencies for several $\mathrm{Al}_{3} \mathrm{P}_{3}$ structures at the HF/6-31G* level of theory. The highest frequency for the low energy structure mentioned above was a totally symmetric mode $\left(\mathrm{a}^{\prime}\right)$ with frequency $551 \mathrm{~cm}^{-1}$, a noticeably lower frequency than the experimental value. In fact, only one $\mathrm{Al}_{3} \mathrm{P}_{3}$ isomer was found to have a frequency as large as our value: planar $\left(D_{3 h}\right) \mathrm{Al}_{3} \mathrm{P}_{3}$ with an $\mathrm{e}^{\prime}$ mode at $631 \mathrm{~cm}^{-1}$. This was for the next-lowest energy isomer found by Raghavachari, so it is possible that $\mathrm{Al}_{3} \mathrm{P}_{3}{ }^{-}$has a similar but lowersymmetry geometry, resulting in activity of the $\mathrm{e}^{\prime}$ mode in the photoelectron spectrum. Higher-level calculations of the vibrational frequencies for the various $\mathrm{Al}_{3} \mathrm{P}_{3}$ isomers would help to resolve this issue.

We conclude by comparing the $\mathrm{Al}_{x} \mathrm{P}_{y}{ }^{-} \mathrm{PE}$ spectra to those previously reported for $\mathrm{Ga}_{x} \mathrm{P}_{y}{ }^{-}$and $\operatorname{In}_{x} \mathrm{P}_{y}{ }^{-}$clusters. ${ }^{13,19,42}$ In general, EA's for comparably sized AlP and GaP clusters are similar and somewhat higher than those for InP clusters. For example, the EA's of $\mathrm{Al}_{3} \mathrm{P}_{3}, \mathrm{Ga}_{3} \mathrm{P}_{3}$, and $\mathrm{In}_{3} \mathrm{P}_{3}$ are 2.450, 2.50, and $1.40 \mathrm{eV}$, respectively. Most of the $\mathrm{Al}_{x} \mathrm{P}_{y}{ }^{-}$photoelectron spectra in Figure 1 are similar in appearance to the corresponding $\mathrm{Ga}_{x} \mathrm{P}_{y}{ }^{-} \mathrm{PE}$ spectra; the spectra that differ the most are $\mathrm{AlP}_{2}{ }^{-}$, $\mathrm{Al}_{4} \mathrm{P}^{-}, \mathrm{Al}_{2} \mathrm{P}_{3}^{-}$, and $\mathrm{Al}_{3} \mathrm{P}_{2}{ }^{-}$. Even though the $\mathrm{AlP}_{2}{ }^{-}$and $\mathrm{GaP}_{2}{ }^{-}$ 
spectra appear dissimilar, they have both been assigned to transitions to a neutral ${ }^{2} \mathrm{~B}_{2}$ ground state and ${ }^{2} \mathrm{~A}_{1}$ excited state, but the splitting is considerably larger in $\mathrm{GaP}_{2}$ (1.25 vs 0.41 eV). ${ }^{42}$ In any case, comparison of the PE spectra indicates that most but not all AlP and GaP neutral and anion clusters in the size range we have studied have similar geometric and electronic structures.

Acknowledgment. This research is supported by the National Science Foundation under Grant DMR-9814677.

\section{References and Notes}

(1) Alivisatos, A. P. J. Phys. Chem. 1996, 100, 13226

(2) Alivisatos, A. P. Ber. Bunsen-Ges. Phys. Chem. Chem. Phys. 1997, 101,1573 .

(3) Ervin, K.; Lineberger, W. C. Photoelectron Spectroscopy of Molecular Anions. In Advances in Gas Phase Ion Chemistry; Adams, N.

G., Babcock, L. M., Eds.; JAI Press: Greenwich, CT, 1992; Vol. 1, p 121.

(4) Cheshnovsky, O.; Yang, S. H.; Pettiette, C. L.; Craycraft, M. J.; Liu, Y.; Smalley, R. E. Chem. Phys. Lett. 1987, 138, 119.

(5) Kitsopoulos, T. N.; Chick, C. J.; Weaver, A.; Neumark, D. M. J. Chem. Phys. 1990, 93, 6108 .

(6) Polak, M. L.; Ho, J.; Gerber, G.; Lineberger, W. C. J. Chem. Phys. 1991, 95, 3053.

(7) Arnold, C. C.; Neumark, D. M. J. Chem. Phys. 1993, 99, 3353

(8) Burton, G. R.; Xu, C. S.; Arnold, C. C.; Neumark, D. M. J. Chem. Phys. 1996, 104, 2757.

(9) Xu, C. S.; Taylor, T. R.; Burton, G. R.; Neumark, D. M. J. Chem. Phys. 1998, 108, 1395.

(10) Negishi, Y.; Kawamata, H.; Hayase, T.; Gomei, M.; Kishi, R.; Hayakawa, F.; Nakajima, A.; Kaya, K. Chem. Phys. Lett. 1997, 269, 199.

(11) Lippa, T. P.; Xu, S. J.; Lyapustina, S. A.; Nilles, J. M.; Bowen, K. H. J. Chem. Phys. 1998, 109, 10727

(12) Jin, C.; Taylor, K. J.; Conceicao, J.; Smalley, R. E. Chem. Phys. Lett. 1990, 175, 17

(13) Xu, C. S.; Debeer, E.; Arnold, D. W.; Arnold, C. C.; Neumark, D. M. J. Chem. Phys. 1994, 101, 5406.

(14) Arnold, C. C.; Neumark, D. M. Can. J. Phys. 1994, 72, 1322.

(15) Thomas, O. C.; Xu, S. J.; Lippa, T. P.; Bowen, K. H. J. Cluster Sci. 1999, 10, 525 .

(16) Asmis, K. R.; Taylor, T. R.; Neumark, D. M. J. Chem. Phys. 1999 111,8838 .

(17) Asmis, K. R.; Taylor, T. R.; Neumark, D. M. J. Chem. Phys. 1999, $111,10491$. 9,257

(19) Taylor, T. R.; Asmis, K. R.; Xu, C. S.; Neumark, D. M. Chem. Phys. Lett. 1998, 297, 133.

(20) Asmis, K. R.; Taylor, T. R.; Neumark, D. M. Chem. Phys. Lett. 1999, 308, 347 .
(21) Balasubramanian, K. J. Phys. Chem. A 2000, 104, 1969.

(22) Korambath, P. P.; Singaraju, B. K.; Karna, S. P. Int. J. Quantum Chem. 2000, 77, 563 .

(23) VanOrden, A.; Saykally, R. J. Chem. Rev. 1998, 98, 2313.

(24) Bruna, P. J.; Grein, F. J. Phys. B: At., Mol. Opt. Phys. 1989, 22, 1913.

(25) Meier, U.; Peyerimhoff, S. D.; Bruna, P. J.; Karna, S. P.; Grein, F. Chem. Phys. 1989, 130, 31.

(26) Allaham, M. A.; Trucks, G. W.; Raghavachari, K. J. Chem. Phys. 1992, 96, 1137.

(27) Rodriguez-Hernandez, P.; Munoz, A. Semiconductor Sci. Technol. $1992,7,1437$.

(28) Tomasulo, A.; Ramakrishna, M. V. J. Chem. Phys. 1996, 105, 10449 .

(29) Feng, P. Y.; Balasubramanian, K. Chem. Phys. Lett. 1999, 301, 458.

(30) Feng, P. Y.; Balasubramanian, K. J. Phys. Chem. A 1999, 103, 9093.

(31) Archibong, E. F.; Gregorius, R. M.; Alexander, S. A. Chem. Phys. Lett. 2000, 321, 253.

(32) Feng, P. Y.; Balasubramanian, K. Chem. Phys. Lett. 2000, 318 , 417.

(33) Xu, C. S.; Burton, G. R.; Taylor, T. R.; Neumark, D. M. J. Chem Phys. 1997, 107, 3428.

(34) Metz, R. B.; Weaver, A.; Bradforth, S. E.; Kitsopoulos, T. N.; Neumark, D. M. J. Phys. Chem. 1990, 94, 1377.

(35) Moravec, V. D.; Jarrold, C. C. J. Chem. Phys. 1998, 108, 1804

(36) Cooper, J.; Zare, R. N. Photoelectron Angular Distributions. In Lectures in Theoretical Physics; Geltman, S., Mahanthappa, K. T., Brittin, W. E., Eds.; Gordon and Breach: New York, 1969; Vol. XI-C., p 317.

(37) Frisch, M. J.; Trucks, G. W.; Schlegel, H. B.; Scuseria, G. E.; Robb, M. A.; Cheeseman, J. R.; Zakrzewski, V. G.; Montgomery, J. A., Jr.; Stratmann, R. E.; Burant, J. C.; Dapprich, S.; Millam, J. M.; Daniels, A. D.; Kudin, K. N.; Strain, M. C.; Farkas, O.; Tomasi, J.; Barone, V.; Cossi, M.; Cammi, R.; Mennucci, B.; Pomelli, C.; Adamo, C.; Clifford, S.; Ochterski, J.; Petersson, G. A.; Ayala, P. Y.; Cui, Q.; Morokuma, K.; Malick, D. K.; Rabuck, A. D.; Raghavachari, K.; Foresman, J. B.; Cioslowski, J.; Ortiz, J. V.; Stefanov, B. B.; Liu, G.; Liashenko, A.; Piskorz, P.; Komaromi, I.; Gomperts, R.; Martin, R. L.; Fox, D. J.; Keith, T.; Al-Laham, M. A.; Peng, C. Y.; Nanayakkara, A.; Gonzalez, C.; Challacombe, M.; Gill, P. M. W.; Johnson, B. G.; Chen, W.; Wong, M. W.; Andres, J. L.; Head-Gordon, M.; Replogle, E. S.; Pople, J. A. Gaussian 98, revision A.9; Gaussian, Inc.: Pittsburgh, PA, 1998

(38) Dunning, T. H., Jr. J. Chem. Phys. 1989, 90, 1007.

(39) Kendall, R. A.; Dunning, T. H.; Harrison, R. J. J. Chem. Phys. 1992, 96, 6796.

(40) Lee, C.; Yang, W.; Parr, R. G. Phys. Rev. B 1988, 37, 785.

(41) Becke, A. D. J. Chem. Phys. 1993, 98, 1372.

(42) Taylor, T. R.; Asmis, K. R.; Gomez, H.; Neumark, D. M. Europhys. J. D 1999, 9, 317.

(43) Taylor, T. R.; Gomez, H.; Asmis, K. R.; Neumark, D. M. Manuscript in preparation. 